\title{
Knowledge and Beliefs Underlying Curricular Expertise
}

\section{Catherine D. Ennis}

Curricular expertise is reflected in teachers' abilities to select and convey content appropriate to the learner within a particular contextual setting and situation. Teachers' knowledge and beliefs are instrumental in the curriculum decision-making process. Knowledge is often defined as factual information that has been agreed upon by scholars within a discipline. Beliefs are more personal and experiential in origin and appear to influence what and how knowledge will be used. Beliefs may also play a part in knowledge disavowal. Disavowal occurs when individuals choose to reject information that might otherwise change current practice. The acceptance or rejection of new knowledge is instrumental in curriculum innovation and in the enhancement of student learning in physical education.

Curricular expertise is reflected in teachers' abilities to select and convey content appropriate to the learner within a particular contextual setting and situation. Defining and elaborating the knowledge and beliefs that provide the foundation for curricular expertise continues to be a complicated and sophisticated endeavor (Schrag, 1992). Cognitive psychologists define knowledge as objective, factual information that has been scrutinized and agreed upon either publicly or within a community of scholars (Nespor, 1987). The parameters are often defined rigidly to delimit and refine the concept for enhanced understanding and parsimony. Knowledge within this definition can be directly measured. Individuals are often described as having or not having knowledge (Case, 1985). Alternative definitions of knowledge often include a more subjective interpretation of the knowledge that a person values or believes to be meaningful (Shuell, 1986). These perspectives present knowledge as personal constructions based on the connectedness of disciplinary knowledge with personal understanding and experiences (Kincheloe \& Steinberg, 1993). Knowledge, when viewed in this way, is closely connected with beliefs. Beliefs are more difficult to measure directly than is factual knowledge. An individual's beliefs often must be inferred from statements or actions. They reflect a tacit understanding of personal, social, or professional truths that have been constructed over time through enculturation, education, or schooling (Schon, 1983; Van Fleet, 1979).

Catherine D. Ennis is with the Department of Kinesiology at the University of Maryland, College Park, MD 20742-2611. 
Curricular expertise depends on a synthesis of knowledge and beliefs about teaching and learning. Knowledge can be subdivided into declarative, procedural, and conditional knowledge. Declarative knowledge is factual information that serves as the foundation for the disciplinary knowledge base; this knowledge must be connected to the student's experience in order to be remembered and used. Procedural knowledge consists of information about how to perform a task. Conditional knowledge is knowledge of "when," "why," and "under what conditions" declarative and procedural knowledge should be used (Paris, Lipson, \& Wixson, 1983). It may include when to use a teaching style or when to introduce the next skill progression (Garner, 1990). Educational beliefs have been described as a form of conditional knowledge. Beliefs influence curricular decisions about content selections, instruction, and evaluation. They influence teachers' judgments about the teaching-learning process. Beliefs are connected to teachers' social systems and may develop in response to political and economic opportunities and limitations within the teaching environment.

Although it is important to define and distinguish among declarative, procedural, and conditional knowledge, some scholars focus on interrelationships among the concepts that contribute to the development of expertise. Recently, researchers have given greater attention to the role of beliefs in the interpretation and evaluation of knowledge (Pajares, 1992). Beliefs can be conceptualized along a continuum from those that are formulated as a result of having knowledge to beliefs that facilitate or limit one's interest in acquiring new or additional knowledge about some phenomenon. It is clear that many educators are interested in a more holistic approach to the traditional knowledge-beliefs dichotomy. They are attempting to determine how a knowledge-beliefs construct influences the development of expertise in teachers and their students. In this article I will briefly describe traditional conceptualizations of knowledge and belief. I will then focus on relationships between the two concepts that promote a greater understanding of curricular expertise.

\section{Describing Knowledge for Curricular Expertise}

Cognitive psychologists conceptualize the development of knowledge within cognitive structures that reside as abstract networks in long-term memory (Snow \& Lohman, 1989). Expertise is associated with the frequency and complexity of information networks and the level of coherence within and across these networks. An individual's knowledge networks function effectively when he or she detects the relationship between a problem of interest and relevant knowledge that is stored in memory. The individual makes connections that link the immediate problem with the knowledge base resulting in one or more possible solutions.

Curricular expertise depends on a broad understanding of the disciplinary knowledge base and the ability to transform this knowledge into content for learning. It is based on the individual's ability to build connections across the disciplinary knowledge base and apply theoretical knowledge to practical situations. For example, a physical education teacher may be concerned that some students in softball class are unable to hit the ball consistently. The teacher searches memory networks, such as those related to biomechanics and motor development, and connects this information to knowledge of skill progressions, developmental requirements for batting, or perceptual considerations associated 
with the swing's timing and placement. The more effectively the teacher's knowledge networks are connected, the more alternative solutions the teacher can generate to teach the batting skill.

\section{Forms of Knowledge}

Knowledge networks consist of declarative, procedural, and conditional knowledge (Anderson, 1985; Garner, 1990). Declarative knowledge is composed of factual information regarding concepts and their interrelationships. Procedural knowledge is knowledge about how to perform or use the information. In the softball example, declarative knowledge includes disciplinary knowledge from biomechanics, motor learning, and development, as well as sport-specific information about the nature of the stance, swing, and follow through. Cues about timing, tracking, and weight transfer also represent a factual understanding of the softball swing.

Teachers' procedural knowledge networks facilitate the organization and retrieval of knowledge about how to perform or how to teach the student to perform the swing. Educators often define procedural knowledge as pedagogical content knowledge (Shulman, 1987). Grossman (1990) proposes four categories of pedagogical content knowledge that facilitate the teaching of skill such as the softball swing. These include the teacher's understanding of how to accommodate instruction to the cognitive, emotional and physical developmental level of the student. For example, 5th-grade students and 11th-grade students often make the same mistake when attempting to hit a softball. Although teachers' analyses of the physical errors might be the same for both students, differences in each student's cognitive and emotional abilities and past experiences require different tasks and teaching cues. Teachers focus on matching the declarative knowledge with a pedagogical understanding of student characteristics within the teaching setting.

Grossman (1990) suggests that teachers' procedural or pedagogical content knowledge should also include an understanding of student conceptions and misconceptions about the skill or the context in which the skill is performed. This is translated into curricular and teaching expertise by reinforcing accurate conceptions or by providing tasks to extinguish misconceptions. Students often have misconceptions about how a skill, such as the softball swing, should be performed. These misconceptions limit chances for success. When correcting student misconceptions about batting, for example, teachers need to point out the importance of a stable base of support and of appropriate timing for weight transfer to enhance student success.

Grossman indicates that a third component of teachers' pedagogical content knowledge is a knowledge of curricular materials for a particular subject. In physical education, this extends beyond a basic understanding of equipment and facilities. Physical educators must be aware of different curricular approaches and must have experience in selecting and teaching these to students. Further, educators use curricular knowledge of tasks and environments to create situations that encourage students to practice a particular skill. Educators may change the rules of the game to reward use of a skill, or they may modify the game to encourage the use of a novel strategy. They can promote the cognitive transfer of concepts across physical activities by assisting students to focus on the common 
characteristics of movement and exercise across different situations. As students make these connections, they are better able to apply skills in novel situations without the teacher's assistance.

The fourth component of pedagogical content knowledge, according to Grossman (1990), is the teacher's knowledge of strategies for teaching particular topics. In physical education this translates into a broad understanding of strategies for teaching fundamental movement, skill, sport, and fitness topics. Teachers must not only have a strategy repertoire, they must also be able to match strategies with particular content and situational requirements, the teaching situation, or the unique characteristics of students. This category of pedagogical content knowledge appears to focus on when content or methods should be used. Paris et al. (1983) and Garner (1990) describe this component as a distinct category of conditional knowledge. Conditional knowledge, or the knowledge of when to use declarative or procedural knowledge, is a critical component of curricular expertise. It is especially relevant when making curricular decisions necessary to teach the "right" content to the "right" child at the "right" time (Jewett, Bain, \& Ennis, in press).

\section{Constructivist Definitions of Knowledge}

In traditional conceptualizations of knowledge, disciplinary information is considered separate from the human being who will teach or learn the information. Recent constructivist approaches to education focus on knowledge connections that individuals make in their lives (e.g., Brooks \& Brooks, 1993). Constructivists argue that expert teachers establish explicit linkages for students between new information taught in class and students' past and future experiences. They help students build knowledge and performance networks by taking skills and concepts learned in one subject area and applying them in other subjects and contexts. Teachers summarize, review, and link main concepts at critical points throughout and at the conclusion of units and lessons. In other words, constructivists believe that active learners store and retrieve information on the basis of meaningful connections among facts and concepts. Transfer and integration of concepts requires individuals to practice using the knowledge in novel situations. They learn to store and retrieve information in a way that is flexible and uniquely meaningful to them.

Critical constructivism, as described by Kincheloe and Steinberg (1993) focuses on "the frontier where the information of the disciplines intersects with the understandings and experience that individuals carry with them to school" (p. 301). This is the point at which knowledge is created or constructed. Curricular expertise within this perspective is used to facilitate interactions between disciplinary and experiential knowledge. Teachers assist students to "reinterpret their own lives and uncover new talents as a result of their encounter with school knowledge" (p. 301). Teachers focus on creating situations in which student experiences can intersect with the disciplinary knowledge base. Cognition becomes a process of knowledge construction. Students are encouraged to focus on the role of knowledge in shaping their lives and in making meaning. Selfreflection becomes a priority for both teachers and students. Each must actively construct the relationships between personal experience and classroom knowledge. 
In physical education, the constructivist perspective is gaining support in the design and implementation of fitness curriculum (e.g., Steinhardt, 1992). Historically, the knowledge base for fitness was presented as factual data that described the physiological effects of exercise on the cardiovascular system. The rationale for student interest and learning was linked with the threat of poor health often in the form of a heart attack. Adolescent students had difficulty perceiving a relationship between their currently robust lives and this seemingly remote outcome. Constructivists propose that more effective approaches to adolescent fitness focus on reasons that adolescents might find meaningful, such as weight management and appearance. Knowledge must initially connect with the students' daily goals and activities. As students make connections, they develop cognitive networks that enhance the meaning of the new information. As students become more fit, the focus changes to emphasize intrinsic motivators such as pleasure and enjoyment of participation. Students are more receptive to the acquisition of new knowledge that can be meaningfully connected. Their developing knowledge structures provide a foundation on which to build meaningful new knowledge relationships that facilitate the commitment to a healthy, active lifestyle.

Kincheloe and Steinberg (1993) describe this perspective as a postformal conceptualization of the cognitive process. Students' lives shape meaning construction. The content that students learn is a product of these interrelationships. They focus not only on what they learn but how they learn. They examine how knowledge gains credibility and acceptance within a culture or society. Students consider political, social, and economic factors that shape the acceptability of different forms of knowledge.

Connectedness is a critical factor in the definition and utilization of knowledge that contributes to knowledge understanding and public acknowledgement of its value. Cognitive psychologists discuss the function of knowledge nodes and networks to explain this phenomena, whereas postformalists emphasize the role of personal experience in creative-meaning making. In each instance, advocates argue that nothing is learned in isolation (Kincheloe \& Steinberg, 1993; Shuell, 1986). Curricular expertise associated with the communication of knowledge requires that educators explicitly assist students to connect prior knowledge to new knowledge and disciplinary knowledge to experience. When examined carefully, this conceptualization leads directly to the central role of beliefs in the construction and utilization of knowledge.

\section{The Influence of Beliefs on Knowledge Acquisition and Utilization}

Nisbett and Ross (1980) conceptualize generic knowledge as composed of two interrelated components. The cognitive component is organized as a schema or knowledge structure, and the experiential component consists of networks of beliefs, values, and attitudes. For instance, teachers may have a knowledge of the school policy on dressing for physical education and a belief that more students will dress when provided with a "loaner uniform." Other physical educators may have knowledge of the role of musculoskeletal structure in the development of strength and power and a belief that boys are better basketball 
players than girls. Beliefs influence decisions associated with evaluation and judgments of content, teaching strategies, and task selection. Nisbett and Ross suggest that beliefs are often viewed as a form of knowledge. When beliefs are strongly held or have been part of the teacher's decision-making structure for a long period, they often act as knowledge to inform the decision-making process.

Rokeach (1968) explains that belief systems are composed of beliefs, attitudes, and values. When beliefs and knowledge are organized or clustered around a phenomenon, they are described as an attitude. Attitudes are clusters of beliefs about something. Attitudes about education, for example, are connected to other interpersonal or social concepts to form a network. The network might include attitudes about schools, community, violence, service, and family.

Beliefs are described as values when they are used for evaluative, comparative, or judgmental purposes. Values are influential in decisions to accept or reject knowledge as feasible, useful, or essential. Teachers must set priorities, evaluate each alternative, and make a judgment about actions most likely to be successful. Values can be described as the utilization of a belief system for decision making. Curricular expertise depends on the effective evaluation and selection of content and tasks to enhance student learning.

Pajares (1992) argues that "beliefs are the best indicators of the decisions that individuals make throughout their lives. Understanding the belief structures of teachers and teacher candidates is essential to improving their professional preparation and teaching practices"' (p. 307). Nespor (1987) identified several features that characterize beliefs. These include existential presumptions, evaluation, and judgment. Existential presumptions are personal truths unique to each individual. They appear to form the foundation for personal and professional belief systems influential in curricular decision making. Belenky, Clinchy, Goldberger, and Tarule (1986) insist that "each of us has a unique perspective that is in some sense irrefutably 'right' by virtue of its existence'" (p. 222). Rokeach (1968) describes existential presumptions as commonsense beliefs that compose one's social and personal reality. They are deeply personal and are rarely affected by persuasion. Teachers' beliefs are formed over their professional careers through chance observations, intense experiences (either positive or negative), or a series of events that gradually convince them of the "truth" of some rationale or relationship.

Individuals create unique belief structures that appear to have stronger evaluative or judgmental characteristics than does factual knowledge (Nespor, 1987). Evaluations and judgments are often made independently of cognitive processes typically associated with factual knowledge. Teachers make decisions based on their tacit, personal values (Schubert, 1990). These decisions range from deciding what content to teach and how much practice time to provide to deciding how stringent to set performance criteria. Both knowledge and beliefs are stored in networks or systems of interrelated concepts. Knowledge appears to be stored in a formal knowledge structure, whereas beliefs are linked with episodes or experiences that determine, in part, when and how the knowledge will be used.

Belief structures are individually constructed and do not rely on group or scholarly consensus, as does knowledge. At times, beliefs appear to lack internal consistency. The organizational structure that governs the utilization of beliefs in judgmental decisions may be linked loosely with past experiences. In other 
words, decisions based on beliefs may be associated with a previous situation in which the response appeared appropriate. Inconsistency may occur when there is a poor match between the present and the past experience.

Ernest (1989) points out that two teachers may have similar knowledge but teach in different ways. He concluded that differences in beliefs about teaching and learning can greatly influence how teachers select and present content to students. Knowledge organization research in physical education (Ennis, Mueller, \& Zhu, 1991; Housner, Gomez, \& Griffey, 1993a) has identified both the similarities among knowledge structures of teachers who have common training and experience and the differences in the ways teachers conceptualize and use the knowledge base. This suggests that some components of knowledge organization are unique to the individual teacher. Each teacher makes sense of knowledge based on past experience. It is likely that beliefs play a key role in the development and utilization of declarative and procedural knowledge for teaching.

Beliefs and knowledge become progressively more entangled or "braided" (Kinchloe \& Steinberg, 1993) when used in curricular decision making. Lewis (1990) argues persuasively that the origin of all knowledge is found in beliefs. He suggests that ways of knowing are basically ways of choosing values. In other words, upon reflection, the socially constructed nature of knowledge can be described as beliefs held by an influential group of individuals.

\section{Implications of Knowledge and Beliefs for Teaching}

Although both knowledge and beliefs are essential components within curricular expertise, it is the interdependence of these concepts that attracts the interest of educational scholars. Beliefs held and reinforced over a long time period increasingly act as a form of knowledge. Curricular expertise results from repeated experimentation with declarative, procedural, and conditional decisions. Teachers' beliefs form as they test their decisions in a variety of situations and settings on a daily basis. They learn to modify their teaching plans to maximize opportunities to work with particular equipment or facilities. They learn how to select and present content to motivate difficult students to become engaged in physical activity.

Much of my research (e.g., Ennis, 1992a; Ennis \& Chen, 1993) has focused on the influence of teachers' educational beliefs or values, described as curricular value orientations, on their goals and objectives for physical education. Curricular value orientations have been described in the literature as beliefs about the educational process (Eisner, 1992). Value orientations describe the relative priority that the teacher places on several key factors in teaching. These include teaching the disciplinary body of knowledge, accommodating student interests and needs in curriculum selection, and responding to or shaping the teaching environment in which the teacher works. Teachers find they must set priorities when time, facilities, and equipment are limited. In physical education, we are often confronted with only a fraction of the time needed to convey the knowledge base to our students. At times students come to our classes unprepared to listen, follow directions, and work independently. Teachers' experiences in working in these situations appear to interact with the knowledge base they acquired in 
teacher preparation. The result is a creative blend of knowledge and beliefs. The teachers develop unique educational belief systems or value profiles (Ennis \& Zhu, 1991) that influence their selection of content, teaching strategies, and tasks in their gymnasium.

Teachers also develop strategies to minimize the potential problems created by crowded classes and limited facilities and equipment. Often the teacher's determination to overcome obstacles is related to the strength of his or her belief in the importance of a task or activity to the education of students (Ennis, Ross, \& Chen, 1992). Teachers expend great effort to find ways to teach content that they believe is important to their students' learning and enjoyment. Conversely, teachers make only minimal efforts to improve situations that limit the teaching of content when they do not believe the content is important. This can occur when teachers are required to implement a new curriculum that they had no part in designing or that is inconsistent with their own professional skills or beliefs. In these instances teachers may choose to ignore information, even when others (researchers, curriculum directors, supervisors) insist that the curricular change will improve the learning environment for their students. Like other beliefs, educational value orientation seems to be influential in screening the knowledge that physical educators are likely to consider and incorporate into their knowledge structures. Once formed, value orientations appear to be resistant to change, creating formidable obstacles to the innovation process.

Scholars have suggested that beliefs may be one of the most valuable psychological constructs in teacher education (Pintrich, 1990), teacher effectiveness research (Fenstermacher, 1979), and curriculum (Eisner, 1992). Certainly our ability to conceptualize the relationships among construct components is critical to our understanding of knowledge and beliefs and of their impact on learning.

\section{Beliefs as Constraints to Knowledge Acquisition}

Pajares (1992) explains that the "earlier a belief is incorporated into the belief structure, the more difficult it is to alter' (p. 325). Nisbett and Ross (1980) suggest that early experiences become woven within belief systems. They appear to influence final judgements across one's career. In the relatively isolated world of teaching, teachers may not have ready access to traditional knowledge or research about an immediate problem. Once teachers make a judgment and find it effective, they are likely to incorporate the solution as part of a belief or informal theory (Clark \& Peterson, 1986). Over time, informal theories become highly resistant to change. These rigid beliefs influence teachers' perceptions of the usefulness of alternative strategies or judgments, influencing their willingness to consider and use new information.

Efforts to maintain one's beliefs in the presence of conflicting information often result in what Pajares (1992) describes as "very agile, mental somersaults" (p. 317). Some researchers (Nespor, 1987; Nisbett \& Ross, 1980) describe efforts by teachers to interpret conflicting evidence to support their beliefs. They may use selective attention to focus only on the information that supports their informal theories or beliefs. These strategies result in biases that limit their ability to question beliefs in light of new information. Biases can influence "not only what 
individuals recall but how they recall it, if necessary completely distorting the event recalled in order to sustain the belief' (Pajares, 1992, p. 317).

Knowledge Disavowal. Individuals may continue to hold beliefs based on incorrect or incomplete knowledge, even after being confronted with knowledge or research findings to the contrary. Individuals may choose to reject or disavow knowledge that conflicts with currently held beliefs. Knowledge disavowal is "the avoidance of knowledge in order to preserve or maintain the status quo or to avoid a difficult choice or threatening situation" (Zaltman, 1983, p. 173). Knowledge disavowal is a political strategy to avoid change (Deshpande \& Kohli, 1989). When knowledge presented is inconsistent or incompatible with the individual's belief system, it will not be positioned in the knowledge structure and will not affect future practice. Although it is true that change for the sake of change is unwise, knowledge disavowal can present a formidable barrier to curricular innovation and the development of expertise.

Knowledge disavowal can be used to preserve one's sense of self-worth or self-efficacy. By attributing failures or difficulties in applying knowledge to constraints in the teaching setting, teachers place the responsibility or locus of control for decisions affecting learning to some other source beyond their control. They can legitimately dismiss knowledge as nonutilitarian because it is not effective in their situation. In other words, when knowledge seems inextricably tied to ideal facilities, motivated students, and supportive administrators, teachers may not perceive its usefulness in their gyms. When one or more of these are not perceived to be present, then of course the innovation will fail. This becomes part of the teacher's set of existential presumptions that eventually becomes impervious to old and new knowledge alike. Knowledge of curricular and instructional innovations becomes inert. It is available but is perceived to be irrelevant.

Knowledge Disavowal in Preservice and In-Service Education. Examples of knowledge disavowal are prevalent in the teacher preparation and staff development literature. Preservice teachers are thought to formulate a belief system about teaching while they are students in primary and secondary school. Lortie (1975) described this as an apprenticeship of observation. This apprenticeship influences conceptualizations about effective teaching, student behavior, and appropriate content. Hutchinson (1990) explored the impact of secondary students' school histories on their willingness to acquire knowledge in professional preparation programs. She found that students' family, involvement in school, and involvement in organized athletics influenced their perceptions of physical education. These students were strongly attracted to sport and saw physical education as a means to a coaching career. They described the central role of the physical educator consistent with goals of class management, participation, and entertainment. This perception constrains physical education teacher educators' abilities to encourage a focus on educational physical education.

Beliefs that are relatively new to the individual must fight for positioning with well-established beliefs in the beliefs network. When beliefs are challenged prior to becoming firmly established, they are easily squeezed out of the structure. Professional preparation faculty may attempt to challenge the preservice teachers' beliefs about physical education acquired from observing a favorite physical educator or coach. They often meet with firm resistance from the preservice teachers. Attempts to instill conceptions of effective teaching contrary to those observed and enjoyed in middle and secondary school often meet with strong 
resistance. Likewise, sustaining neophyte beliefs recently developed in professional preparation is difficult when confronted with the persuasive views of veteran teachers and traditional school policies. These views may encourage firstyear teachers to revert to earlier beliefs and expectations of physical education formed while in middle and high school physical education.

Staff developers are often faced with resistance when attempting to present an innovation to in-service teachers. Faucette (1987) categorized teachers' participation levels in a movement education innovation as assimilators, conceptualizers, and resistors. Assimilators found the proposed innovation consistent with their present knowledge structures and belief systems. They were highly motivated to try the new curriculum in their classrooms. They already possessed many of the declarative and procedural knowledges necessary to implement the change. Conceptualizers evaluated the innovation as consistent with their current knowledge and beliefs, but felt they did not yet possess sufficient information to implement the program in their classrooms. Resistors judged the innovation to be incompatible with their current conceptualization of physical education. They expressed personal and informational concerns and cited environmental problems, such as large class sizes, that were barriers to success. The innovations may have been inconsistent with their beliefs or knowledge structures. They disavowed the knowledge about movement education provided in the in-service, expressing concerns about the compatibility of the innovation with their school setting. They stated that the workshop leaders were unaware of the problems associated with teaching in their school.

Teacher concerns are the result of beliefs about one's professional ability, knowledge, and setting. Teacher concerns have been examined by several researchers in physical education (Boggess, McBride, \& Griffey, 1985; Knowles, 1981; McBride, Boggess, \& Griffey, 1986; Schempp, 1986; Wendt \& Bain, 1989). Concerns range from personal concerns regarding the demands of the innovation on teacher energy and time to management concerns about the teacher's ability to teach effectively using the innovation. Other concerns focus on the consequences or impact of the innovation on student learning. Schempp (1986) examined student teachers' concerns or beliefs about their ability to control their students and influence student learning. His study examined beliefs about self-efficacy or belief in one's ability to be successful. He found that student teachers with high self-efficacy were able to control their classes and enhance student learning more effectively than those who were less sure of their ability.

\section{Connecting Knowledge With Beliefs}

Efforts to conceptualize a holistic approach to curricular expertise must focus on the interrelatedness of knowledge and beliefs in the curriculum decisionmaking process. Dynamical systems theory is one paradigm than can be used to describe the complex, dynamic relationships between knowledge and beliefs within the teaching-learning process (Cziko, 1989; Rockler, 1990/1991). Briefly, this theory acknowledges the interrelatedness of every aspect of the educational setting. Some aspects, described as attractors, seem to be more influential in the teaching-learning process than others. Attractors influence decisions regarding the overall organization and functioning of the system. We can hypothesize that beliefs act as attractors to influence many of the decisions that teachers make in 
the gym (Ennis, 1992b). For example, if teachers believe it is important to teach students to work cooperatively with others, they are likely to devote time to teaching cooperative skills separate from traditional games content. They design tasks that require progressively more complicated cooperative skills, and evaluate their own and their students' success by the extent to which students can work together to accomplish skill, sport, and exercise goals.

Although attractors are influential within a dynamical system, such as a physical education classroom, they can be limited by constraints in the environment. Constraints include students who do not come to school ready to learn, limited equipment, time, and large class sizes that prevent teachers from structuring and controlling the learning environment. In other words, attractors, such as a teacher's belief system, can be influential only when student and environmental factors can be shaped to conform with the teacher's educational vision. When they cannot, teaching quality and effectiveness diminish. For instance, a teacher with a strong belief in the importance of increasing student skill level may be constrained by administrative decisions to schedule 50 students in the sixthperiod class. Budget limitations also can constrain the teacher's ability to purchase needed equipment to enhance opportunities for practice.

An attractor's influence is thought to cascade throughout the teaching setting. Belief systems within the gym might be influential at several different decision-making levels. For example, a teacher might argue persuasively in a summer curriculum-writing committee for the importance of allowing students to make choices about the content they would like to learn in high school physical education (e.g., Ennis, Mueller, \& Hooper, 1990). Committee members may describe numerous examples of student decision making in lesson plans included in the curriculum guide. Teachers who agree with the goal of enhancing student responsibility experiment with these ideas, modifying and creating additional opportunities for student decision making in their classes. Student teachers working in these schools have the opportunity to observe working models and to design their own tasks to enhance student decision making. Students are encouraged to set and monitor personal goals throughout the year. They, in turn, feel the effect of the belief system and make progress in personal decision making essential to the development of healthy, active lifestyles.

\section{Conclusion}

Knowledge and beliefs are partners on the road to curricular expertise. Although we currently focus much of our attention in professional preparation on the development of preservice teachers' declarative and procedural knowledge base, conditional knowledge or beliefs may be an equally influential factor in the acquisition, organization, and utilization of knowledge for teaching. Preservice teachers need opportunities to develop and test their own beliefs associated with the selection and utilization of knowledge for teaching. Knowledge that is made meaningful and useful to them at their own stage of professional development is critical to the development of effective teaching skills. Preservice teachers also need assistance to connect disciplinary knowledge to past and present experiences in their lives. In turn, they develop curricula that are meaningful and useful to their students. Preservice teachers become more sensitive to the personal and 
social characteristics of students and can assist them to connect the physical education content to meaningful experiences in their lives.

When knowledge and beliefs are examined separately, it is difficult to conceptualize the full impact of beliefs on teaching and learning. The answers to curricular questions such as "What is learned?" "Why it is learned?" and "What knowledge is most important to these students in this physical education class?" depend on the interaction of knowledge and beliefs in the decisionmaking process. Curricular expertise results from blending knowledge and beliefs to form a commitment to student learning. It is likely that preservice teachers build unique values and belief systems from a relatively common disciplinary and procedural knowledge base. Over time experiences shape and enhance the complexity of their knowledge structures necessary to adapt to the unique settings and situations in which they teach.

Curricular expertise is manifest in a clear understanding of declarative and procedural knowledge braided within a belief system that facilitates the when and why decisions critical to curricular decision making. It reflects the teacher's ability to make contextually appropriate decisions about students and the knowledge base when planning and teaching. It promotes a holistic perspective that gives appropriate weight to the role of knowledge and the needs of the learner within particular settings and situations. Connections developed with expertise cascade throughout the planning-teaching-learning environment to enhance student learning across the physical education curriculum. 